\title{
Ceticismo nas Relações Internacionais: o caso europeu
}

\author{
Estevão de Rezende Martins ${ }^{1}$ \\ Professor da Universidade de Brasília - UnB \\ echarema@gmail.com
}

Como citar este artigo: MARTINS, E. C. R.“Ceticismo nas Relações Internacionais: o caso europeu”, Intelligere, Revista de História Intelectual, nº10, pp. 244-259. 2020. Disponível em <http://revistas.usp.br/revistaintelligere>. Acesso em $\mathrm{dd} / \mathrm{mm} /$ aaaa:

Resumo: O ceticismo aparece na cena política e social internacional na forma de uma descrença crescente, entre os cidadãos, quanto ao sistema político notadamente quanto à democracia mesma - à forma de governar e às relações entre os Estados. Na Europa, tal ceticismo atinge o cerne mesmo da construção europeia e as oscilações da opinião pública, como captadas pelo Eurobarômetro, apontam para os riscos de tal instabilidade.

Palavras-chave: União Europeia; democracia; ceticismo; opinião pública.

\section{Skepticism in International Relations: the European case}

\begin{abstract}
Skepticism appears on the international political and social scene in the form of a growing disbelief, among citizens, about the political system notably regarding democracy itself - the way of governing and the relations between States. In Europe, such skepticism reaches the very heart of the European construction and the fluctuations in public opinion, as captured by the Eurobarometer, which points to the risks of such instability.
\end{abstract}

Keywords: European Union; democracy; skepticism; public opinion.

1 Professor titular emérito da Universidade de Brasília. PhD (Munique, Alemanha, 1976). Pesquisador CNPq 1A (História). Ex-Presidente da Sociedade Brasileira de Teoria e História da Historiografia (2009-2015). Vice-presidente da Comissão Internacional de História dos Parlamentos e Instituições Representativas (desde 2011). Contato: echarema@gmail.com Lattes: http://lattes.cnpq.br/8217850863705574 
A cena internacional é uma arena de desconfianças constantes. O euroceticismo tornou-se praticamente um clássico nos últimos vinte anos.

Em que consiste o euroceticismo?

O termo tem sido usado em discussões políticas por cerca de duas décadas para qualificar uma vasta gama de atitudes em relação à União Europeia, com respeito a determinadas políticas específicas ou, genericamente, para uma rejeição categórica de todo o projeto europeu, desde seu nascedouro.

Os alvos do euroceticismo podem incluir o projeto europeu de integração como um todo, a estrutura atual da UE, decisões concretas em domínios políticos setoriais da UE ou determinados projetos para o desenvolvimento e consolidação da integração comunitária ("aprofundamento" e "alargamento") (DE VRIES, 2018).

Tais atitudes são próprias, em primeiro lugar, a determinados partidos políticos, como a Frente Nacional (França), a Alternativa para a Alemanha, a Lega Norte (Itália), o Partido pela Liberdade (Holanda) ou o Partido Liberal (Áustria). O rótulo de "eurocético" é também atribuído a partidos que se distribuem por todo o espectro político - isto é, não apenas partidos dos dois extremos - desde que suas tomadas de posição incluam elementos que colocam a integração europeia como prejudicial, duvidosa ou mal-vinda (MILIOPOULOS, 2017, p. 58-76).

Como o espectro de significados do termo 'euroceticismo' é amplo, importa tipificar os sentidos mais usuais de seu emprego. Pode-se distinguir de início entre um euroceticismo "duro" e um euroceticismo "brando". O euroceticismo duro denota rejeição total de todo e qualquer formato de integração europeia, proclamando o fracasso da jornada desde 1950 e advogando a restauração da soberania e da identidade nacional de cada país no interior de suas fronteiras atuais (sem cuidar de saber a história da geopolítica europeia dos últimos duzentos e cinquenta anos) e sair da União Europeia de imediato. O euroceticismo brando é seletivo, situa-se na crítica moderada a certas regras (como o da transferência total de soberania nacional para o ente supranacional UE). Essa distinção parece óbvia. Com efeito, o euroceticismo brando se dilui e tem impacto difuso e impreciso - mas atinge a opinião pública e se reflete nas pesquisas de opinião, como se verá mais adiante. O 
euroceticismo duro se instala em partidos políticos nacionais e impacta tanto as eleições internas quanto às eleições europeias (notadamente pela abstenção e pela eleição de eurodeputados "anti-Europa", como no caso do UKIP britânico ou da Frente Nacional francesa).

Há ainda outras tipificações do euroceticismo, que apontam a diversidade e a complexidade de reunir sob uma única categoria uma miríade de perspectivas e ambições políticas, quase todas enraizadas em questões locais, regionais e nacionais.

Em primeiro lugar, atribui-se particular importância à ideologia, em relação aos partidos, ou seja, às suas convicções, valores e objetivos básicos. Um euroceticismo moldado ideologicamente afirma que os valores que lhe são próprios seriam incompatíveis com as características centrais da UE e de sua política.

Em segundo lugar, um partido pode ser guiado por considerações estratégicas; utilizaria então a sua posição eurocética de forma oportunista para aumentar a sua visibilidade e fortalecê-la perante os outros partidos, ou seja, instrumentalizá-la em benefício dos objetivos políticos internos na competição política.

Um terceiro tipo de euroceticismo é de cunho utilitarista: a questão posta indaga que benefícios econômicos a adesão à UE auferiu ou prometeu trazer para o país, ou quais desvantagens - talvez apenas em áreas políticas específicas - a adesão poderia ter acarretado.

Uma quarta expressão de euroceticismo está enraizada em uma fixação na soberania do Estado. O projeto de integração suscita aqui preocupações, se tocar no que se considera elemento central inalienável da soberania em cada caso particular, mesmo que não passe de mera partilha negociada de soberania. No entanto, o reforço regular e constante das instituições comunitárias - em particular da Comissão e do Parlamento Europeu - ou a aplicação crescente do princípio de maioria ponderada nas deliberações do Conselho são considerados inaceitáveis pelos representantes deste grupo.

Uma quinta forma de euroceticismo aparece na ansiedade com a perda da identidade (nacional) como resultado da integração progressiva ou de decisões em áreas de política que são vistas como uma ameaça a essa identidade. Nos partidos que se situam na extrema esquerda ou direita do 
espectro político, podem ser encontradas atitudes eurocéticas de diversos graus, que não remontam a um único contexto de justificação.

Euroceticismo também molda as atitudes e políticas de alguns partidos situados no centro do espectro político, independentemente de funcionarem como governo ou como partidos de oposição. Partidos e políticos que receberam o rótulo de "eurocéticos" muitas vezes recusam tal etiqueta, camuflando-se atrás do argumento de que suas atitudes e políticas nada mais fazem do que refletir "eurorrealismo".

A desconfiança figadal com relação à Europa sempre foi vista como uma mania britânica. Essa aversão remonta a pelo menos às guerras napoleônicas, mas vem de mais longe, quando da expansão da navegação oceânica e da implantação dos impérios coloniais (MARTINS, 2012)

Tal aversão ainda não se chamava "euroceticismo". Esse conceito foi forjado depois de o processo europeu de integração começar a dar certo e a gerar conflitos - reais ou imaginários - entre o interesse coletivo (a União Europeia) e o interesse particular (os nacionalismos dos estados-membros).

Em épocas de fartura e bem-estar, viva a Europa! Dela se auferem as mais inomináveis vantagens particularizadas. Dois exemplos: (1) a PAC (política agrícola comum), que se mantém graças a um artifício criado por pressão francesa (política do "assento vazio" em 1965/66) e afinal consagrado no assim chamado compromisso de Luxemburgo, de janeiro de 1966. (2) O outro exemplo é a série de "cláusulas de exceção" que se inaugura com a entrada da Grã-Bretanha nas Comunidades Europeias em 1972 e que reproduz o sistema da PAC em diversos outros campos (notadamente o da pesca nas águas territoriais comunitárias), com vantagens desproporcionais ao Reino Unido. Tais cláusulas existem também quanto a outros países (Suécia, Dinamarca, por exemplo) e campos (Espaço Schengen, euro).

Quando as crises sucessivas se acumulam, tanto pela instabilidade econômica mundial quanto pelas diversas etapas de alargamento das Comunidades, se esboça um mecanismo de desconfiança mútua entre os estados-membros e de diversos deles com relação à gestão comunitária sediada em Bruxelas. Políticos "nacionais" se comprazem em acusar a Europa de ser a fonte de todos os males e de todas as imposições, que descaracterizariam a identidade de cada sociedade. 
Mas o euroceticismo agora se espalhou pelo continente como um vírus. Como os dados do Eurobarômetro ${ }^{2}$ mostram, a confiança no projeto europeu caiu ainda mais rápido do que as taxas de crescimento econômico na primeira década do século 21. Desde o início da crise do euro, a confiança na União Europeia caiu de 10 a 22 por cento na França, de 20 a 29 por cento na Alemanha, de +30 a $-22 \%$ na Itália, de +42 a $-52 \%$ na Espanha, de +50 a $+6 \%$ na Polônia e de -13 a -49\% no Reino Unido.

O mais impressionante é que bom número de pessoas na UE parece perder a fé no projeto: credores e devedores e zona do euro, países candidatos e potenciais demissionários (“opt-outs”). Em 2007, as pessoas pensavam que o Reino Unido, que marcou $-13 \%$ em confiança, era o eurocético campeão. Agora, notavelmente, os quatro maiores países da zona do euro têm níveis ainda mais baixos de confiança nas instituições da UE do que a Grã-Bretanha em 2007. Então, o que ocorreu?

A velha explicação para o euroceticismo foi a alegada existência de um déficit democrático na UE. Decisões, críticos disseram, foram tomadas por instituições sem a responsabilidade dos governos nacionais eleitos. Mas a crise atual nasce não de um conflito entre Bruxelas e os estados-membros, mas de um choque entre as vontades democráticas dos cidadãos no norte e sul da Europa - o chamado centro e periferia. E ambos os lados agora estão usando instituições da UE para promover seus interesses.

No passado, havia uma regra não escrita de que as instituições da UE supervisionariam o mercado único e outras áreas técnicas das políticas públicas - como um padrão comum para a composição da massa de tomate ou para emissões sonoras do cortador de grama - enquanto os governos nacionais continuariam a ter o monopólio da prestação de serviços e da formulação de políticas nas áreas mais sensíveis que pudessem pesar de uma ou outra forma nas eleições nacionais respectivas.

Desde o início da crise em 2008, os cidadãos dos países credores resistem a assumir a responsabilidade pelas dívidas de outros sem ter mecanismos para controlar seus gastos. Com o pacto fiscal e as exigências do

2 Criado em 1973, o Eurobarômetro analisa, periodicamente, as tendências e a evolução da opinião pública sobre diversas questões europeias, em todos os estados-membros da UE, por iniciativa das instituições europeias. 
Banco Central Europeu (BCE) de uma ampla reforma do mercado interno, os eurocratas cruzaram muitas das 'linhas vermelhas' relativas à soberania nacional, estendendo seu alcance bem além de alimentação ou normas de segurança para exercer controle sobre pensões, impostos, salários, mercado de trabalho e empregos públicos. Essas áreas estão no cerne das políticas internas de bem-estar e identidades nacionais.

Para um número crescente de cidadãos dos países do sul da Europa, a UE se parece crescentemente com o Fundo Monetário Internacional (FMI) e a política que adotou na América Latina: uma camisa de força dourada que restringiria o espaço para a política nacional e esvaziaria suas democracias nacionais autônomas. Nesta nova situação, os governos vêm ou vão, mas as políticas permanecem basicamente as mesmas, sem admitir contestação. Enquanto isso, na percepção dos países do norte europeu, a UE tem cada vez mais dificuldades em controlar as políticas dos países do sul. Os credores nutrem um sentimento de serem vítimas de exploração, que espelha um sentimento análogo dos devedores.

Se a soberania é entendida como a capacidade de o povo decidir de modo absoluto o que quer para seu país, poucos cidadãos hoje, no norte ou no sul da UE pensam que são soberanos. Uma parte substancial da democracia teria desaparecido no nível nacional, mas não teria sido compensada no nível europeu.

Num sistema político nacional em pleno funcionamento, os partidos políticos poderiam expressar essas diferentes perspectivas - e pretender servir de referência para encontrar um terreno comum entre elas. Mas é precisamente isso que o sistema político europeu não tem conseguido cumprir plenamente: porque carece de partidos políticos efetivos, de um governo adequado e de uma esfera pública, a UE não tem conseguido superar as falhas das democracias nacionais.

Em vez de uma batalha de ideias, a UE está entravada por um círculo vicioso entre o populismo anti-UE e os interesses tecnocráticos acordados entre os estados-membros, que não levariam suficientemente em conta o espectro de expectativas de seus cidadãos (MARTINS, 2013).

A ascensão do populismo anti-UE veio para ficar? A esperança é que, à medida que o crescimento econômico aumente, o euroceticismo enfraqueça e 
eventualmente retroceda. Mas o déficit de confiança na UE vai mais fundo do que isso. $\mathrm{O}$ entusiasmo pela UE não voltará, a menos que a UE mude profundamente a maneira como lida com seus estados-membros e seus cidadãos.

Tomemos alguns exemplos, nem sempre presentes nas grandes análises internacionais correntes, que amiúde se concentram no famoso "casal 20" da UE, França e Alemanha (Martins, 2013).

Com uma União agora sem o Reino Unido, a redistribuição das cartas tem de ser acelerada. A histeria política interna e internacional, que levou a Grã-Bretanha a formalizar seu abandono da UE, escancarou a possibilidade de novo tipo de pressão (alguns diriam: chantagem): considere esse ou aquele governo nacional ter seus 'interesses nacionais' contrariados pela União, brandiria a ameaça de abandonar o barco. Como no caso da Grã-Bretanha, a conta de benefícios comunitários auferidos pelos estados-membros é amplamente favorável à União - assim o uso populista da crítica à 'superpotência de Bruxelas', que 'asfixiaria o pobre cidadão no fundo de seus rincões' se torna ferramenta de jogo político interno. Foi assim que o governo conservador de David Cameron, ambicionando ganhar as eleições de 2015 (e conseguiu) fez a 'promessa do fim do mundo': realizar referendo sobre a permanência da Grã-Bretanha na União. No ano seguinte, deu no que deu: o referendo mostrou os desequilíbrios nacionais internos ao Reino Unido [pelo que alguns comentaristas passaram a falar de 'Reino Desunido' (CLARK, 2010), Cameron caiu e seguiram-se mais de três anos de confusão política e econômica até o desfecho do "brexit" em 31 de dezembro de 2020.

A redistribuição das cartas políticas da arquitetura institucional da UE começou com a crise financeira de 2008/2009, que atingiu duramente tanto a economia quanto o controle das despesas públicas de todos os estadosmembros. ${ }^{3}$ Isso não é uma característica europeia - nem foi na Europa que a bola de neve dessa crise começou a rolar. No século 21, qualquer choque abrupto na frágil estabilidade econômica mundial repercute em toda parte, mundo afora.

3 O início foi a crise das hipotecas americanas. Ver The Financial Crisis Inquiry Report Authorized Edition: Final Report of the National Commission on the Causes of the Financial and Economic Crisis in the United States. Public Affairs, 2011. 
Para ilustrar a volatilidade do euroceticismo tal como aparece nas percepções nacionais, os exemplos utilizados cobrem estados-membros em diversos estágios políticos e econômicos na história da UE, desde fundadores até 'sócios' caçulas:

- fundadores (1958): Alemanha, França, Holanda, Itália

- 1973: Dinamarca; 1981: Grécia; 1986: Espanha, Portugal; 1995: Finlândia; 2004: Polônia, República Checa; 2007: Bulgária.

Alemanha

Os alemães se veem como vítimas da crise do euro. Eles sentem que foram traídos e temem que lhes seja pedido para pagar impostos mais altos ou aceitar níveis mais altos de inflação para salvar o euro (ou mais recentemente, para suplantar a recessão causada pela COVID-19) Embora a Alemanha seja genericamente conhecida por nutrir um sentimento positivo com relação à UE - e no conjunto atue oficialmente nesse sentido - há registro de um afastamento da opinião pública, nos últimos dez anos, quanto ao 'objetivoideal' "Europa": os dados do Eurobarômetro mostram que 56 por cento dos alemães "não confiam" na UE, enquanto apenas 30\% têm uma imagem "bastante positiva" da UE. No entanto, ao mesmo tempo, o populismo foi contido até agora: todos os partidos políticos dominantes apoiam o euro e recentes pesquisas mostram que três quartos dos alemães são contra sair do euro. Um novo partido antieuro, Alternativa para a Alemanha, criado em 2013, já pesa negativamente no cenário político alemão atual. Mesmo que a UE represente para alguns um peso a carregar, a maioria dos alemães considera a União uma moldura política e econômica de alta qualidade.

\section{França}

Pela primeira vez, a França não é exceção: desde o início da crise, a confiança na UE diminuiu e sua imagem piorou. Em 2012, o número de entrevistados franceses que "tendem a não confiar na UE", subiu para 56\%, ante $41 \%$ em 2007. Isso inclui um julgamento negativo sobre a resposta da UE às crises, já tendo impacto na política francesa: é sem dúvida um fator no fortalecimento ainda mais profundo da rejeição radical da UE, como proclamada pela Frente Nacional, de extrema direita, na vida política da 
França. É igualmente um fator significativo (e fácil) do sucesso político e midiático do líder de esquerda radical Jean-Luc Mélenchon. No entanto, no seio da sociedade francesa se mantém uma atitude de vislumbrar na UE um meio visível e decisivo, como uma liderança responsável para viabilizar e enquadrar a recuperação econômica, concentrando-se na redução da dívida, nas estratégias de investimento e políticas de crescimento e, de fato, na capacidade de assegurar um bem-estar pan-europeu. A atitude eurocética é, pois, minoritária.

Holanda

O apoio holandês à UE caiu de $+44 \%$ em 2007 para -8 por cento em 2012. O principal motivo foi o sentimento de ter havido um fraco desempenho dos países da UE e da zona do euro ao lidar com a crise. Em particular, os holandeses veem a UE como parte do problema e não da solução. O resgate da economia grega em 2010 foi objeto de matérias fortemente críticas e constantes na imprensa sobre fraude e má gestão nos países devedores. Partidos populistas se aproveitaram. Os políticos também são suspeitos de usar a meta de déficit fiscal máximo de 3\% para justificar cortes orçamentários impopulares. Embora a Europa tenha sido um problema nas campanhas eleitorais em 2012, seu impacto real nos resultados foi limitado. O Partido Liberal-Democrático (VVD, moderadamente eurocético) e a centro-esquerda (PvdA, Partido do Trabalho, pró-europeu). O PvdA lidera junto com os demais de centro-direita, enquanto os partidos antieuropeus não conseguiram lucrar do crescente euroceticismo dos eleitores (FvD, Fórum pela Democracia; PVV, Partido pela Liberdade). Pesquisas recentes de opinião indicam que os holandeses continuam a apoiar majoritariamente o pertencimento à UE.

\section{Itália}

A austeridade está mudando as percepções da UE entre os cidadãos italianos - especialmente entre os jovens, $40 \%$ dos quais estão desempregados. A recente eleição italiana mostrou que os italianos perderam a fé e paciência com Bruxelas e Berlim e não acreditam mais que o fim da crise estaria próximo. Embora a confiança na UE tenha oscilado na Itália sob pressão dos partidos neonacionalistas, soberanistas e eurocéticos (Lega Norte, Movimento 
5 Stelle), a maioria dos entrevistados italianos ainda se vê cidadãos europeus e identificam-se com a Europa. Em uma pesquisa recente, apenas 1\% queria sair da UE. Em vez disso, uma grande maioria - especialmente entre integrantes do empresariado - quer avançar para uma verdadeira união política que seja mais democrática e mais social do que o formato atual da UE. A pesquisa não mostrou que os italianos querem menos Europa. Pelo contrário, eles querem uma Europa diferente: uma que seja mais flexível e mais simétrica, menos focada na austeridade e mais focada no investimento na economia real.

\section{Dinamarca}

Embora 2012 tenha sido o quadragésimo aniversário da adesão da Dinamarca à UE, parece que os dinamarqueses pró-europeus não tiveram muito para comemorar. A confiança líquida na UE diminuiu de $+36 \%$ em 2007 para apenas $+2 \%$ em 2012. Esta queda se deveu a questões de apoio popular insuficiente, já que a Dinamarca fica de fora da parte mais integrada da UE (como o euro, por exemplo), uma vez que - constitucionalmente - não pode estender seu engajamento sem obter maioria eleitoral por referendo. Dois dos seis referendos realizados no passado foram perdidos pelo campo pró-UE: tal acarretou, por exemplo, alterações no tratado de Maastricht (1992) que excluíram os itens de defesa, justiça e assuntos internos e da moeda única, e estabeleceu a base jurídica para uma Europa a duas velocidades. Por causa do crescimento do euroceticismo, a primeira-ministra Helle Thorning-Schmidt (entre 2011 e 2015) adiou o referendo sobre a Europa que prometera em sua plataforma eleitoral. Isso significa que a Dinamarca seria incapaz de acompanhar os países da zona do euro em um sistema bancário e fiscal ou em uma união política.

\section{Grécia}

Antes do início da crise em 2012, a adesão à UE sempre esteve associada na Grécia ao progresso econômico, à prosperidade e à modernidade, superando o atraso imposto pelo regime totalitário entre 1967 e 1974. A Grécia passou, no entanto, por severa recessão e teve de adotar drásticas medidas de austeridade, reforma estrutural e ajustes financeiros. Sem surpresa, essa experiência traumática levou a uma queda vertiginosa no apoio grego à UE: em 
2007, o apoio líquido foi de +26 por cento; em 2012, era de $-63 \%$. O apoio popular dos dois maiores partidos políticos, Nova Democracia e PASOK, também entrou em colapso. O principal beneficiário foi Partido Syriza (extrema esquerda), que se opunha ao programa de austeridade acordado com a "troika" (FMI, Comissão Europeia e Banco Central Europeu), mas acabou por ser obrigado a ceder, pois a Grécia sempre quis manter o euro e salvar suas finanças. O espaço público ficou fortemente agitado com manifestações "antiBruxelas" e anti-imigrantes. O apoio a partidos explicitamente anti-UE como o KKE comunista e a extrema direita Chryssi Avgi (Aurora Dourada) também aumentou, mas não alterou o espectro político radicalmente.

\section{Espanha}

Durante décadas, a Espanha viu sua relação com a Europa através dos olhos da fórmula de José Ortega y Gasset: "A Espanha é o problema e a Europa é a solução. " O dramático declínio sem precedentes da confiança na UE desde a crise não é simplesmente resultado da austeridade. Afinal, foi através de reformas dolorosas que a Espanha conseguiu aderir à UE e, mais tarde, ao euro e assim superar seu passado difícil. Agora, no entanto, a falta de uma visão clara sobre o futuro nacional ou europeu significa que não há consenso ou legitimidade para os sacrifícios que estão sendo exigidos dos espanhóis, o que desequilibra os resultados eleitorais internos e submete a tensão a complexa tessitura do sistema semifederal do estado espanhol. Os espanhóis não culpam a Europa pela crise e não querem sair do euro. O que parece ter abalado sua lealdade e confiança na Europa é que eles pensam não ser ouvidos nem poder contestar ou alterar políticas públicas. Os espanhóis não se tornaram eurocéticos - mas se transformaram em eurocríticos implacáveis.

\section{Portugal}

O consenso pró-europeu no cerne da política portuguesa foi abalado pela crise do euro: o apoio líquido à UE caiu de $+41 \%$ em 2007 para -24\% em 2012. Os três principais partidos haviam labutado para Portugal estar no centro da integração europeia, o que foi associado a progresso econômico e a estabilidade política. No entanto, isso também levou à estagnação após 
Portugal ingressar na moeda única, apesar das vantagens relativas da produtividade e competitividade econômica. Medidas severas de austeridade e reformas após o início da crise levaram de início a relativamente poucas manifestações violentas e pouca agitação. Mas a profunda recessão acarretou mais inquietação pública, com rejeição da situação de Portugal, que se acreditava sofrer imposição descabida de austeridade - sobretudo por pressão da Alemanha. Os governos de Pedro Passos Coelho e de Antonio Costa perseveraram no engajamento na UE e obtiveram mais liberdade quanto às metas orçamentárias. Assim, a opinião pública portuguesa manteve-se filoeuropeia.

Finlândia

As atitudes em relação à UE na Finlândia são ligeiramente contraditórias: enquanto os níveis de apoio à adesão finlandesa da UE e à moeda única parecem elevados, os níveis de confiança na UE são baixos e há pouca consciência de uma identidade europeia. A crise econômica polarizou os finlandeses e o apoio financeiro aos países endividados da zona do euro é particularmente controvertido. O forte aumento do euroceticismo na Finlândia impulsionou o partido True Finns, que se tornou o terceiro maior partido no parlamento, com 39 cadeiras, nas eleições gerais de 2011. Mas o aumento das críticas à UE levou também a um fortalecimento de sentimentos pró-europeus entre seus apoiadores. Isso sugere que enquanto seja possível que certos finlandeses obtenham capital político mobilizando a insatisfação com a UE, é pouco provável que tal consiga minar o amplo apoio à UE.

\section{Polônia}

Em maio de 2012, pela primeira vez desde que a Polônia entrou na UE, a percentagem de polacos que "tendem a não confiar" na UE (46\%) foi superior à porcentagem de poloneses que "tendem a confiar" nela (41\%) - uma evolução notável para um país tradicionalmente pró-europeu. A UE ainda tem, contudo, índices de aprovação mais altos que o governo, o parlamento ou a televisão pública. No entanto, a UE parece ter perdido sua reputação como âncora da estabilidade para um país que passa por uma enorme transformação de sua situação social e econômica. Em particular, os poloneses são céticos 
sobre o futuro da moeda comum e apenas 29\% desejariam aderir. Essas atitudes públicas representam um dilema para a elite política do país, cuja ambição é estar no centro do poder na Europa. O objetivo da Polônia nos próximos anos seria permanecer o mais próximo possível do núcleo de poder defendendo a integridade de todo o projeto da UE. As circunstâncias políticas internas desde 2015 comprometem seriamente tal atitude inicial.

\section{República Checa}

Tem havido um declínio constante do apoio à UE na República Tcheca: caiu de $+29 \%$ em 2007 para $-26 \%$ em 2012. Os checos têm uma abordagem pragmática em vez de atitude idealista em relação à UE: eles veem a adesão à UE como um "casamento de conveniência", que proporciona prosperidade e segurança. No entanto, a crise comprometeu a imagem da UE como uma comunidade de prósperos. Ao contrário dos eslovacos, que aderiram à moeda única, os checos parecem satisfeitos de não precisar contribuir para as operações de resgate dos países do sul da zona euro do sul, vistos como relativamente irresponsáveis. Por outro lado, os checos não veem ameaça alguma a sua segurança, que poderia fazê-los pensar a UE como necessária para sua proteção. Os governos checos recentes, liderados por eurocéticos moderados (e até obstinados como o ex-presidente Václav Klaus), também contribuíram para um ambiente difuso anti-UE.

\section{Bulgária}

A confiança na UE aumentou ligeiramente desde o ingresso da Bulgária em 2007: 60\% "tendem a confiar" na UE em 2012, em comparação com 54\% em 2007 (embora a desconfiança também tenha aumentado ligeiramente, de $21 \%$ para 24\%). Os cidadãos confiam mais Bruxelas por causa da impopularidade das instituições domésticas (a pesquisa mais recente do Eurobarômetro sugeriu que $74 \%$ desconfiam do parlamento nacional e $79 \%$ têm uma visão negativa dos partidos políticos). A UE continua a servir como um corretivo externo para políticas disfuncionais em casa - ilustrado pela onda de protestos em massa em fevereiro e março de 2012, que desencadeou eleições parlamentares antecipadas, em 2014. Embora a rejeição popular se dirija contra as elites búlgaras, responsabilizadas pela pobreza e corrupção 
desenfreadas, a UE não era mais invocada como solução. Investidores privados de outros estados-membros também foram criticados, conduzindo a um movimento em direção ao nacionalismo econômico, que também pode preparar o terreno para o possível euroceticismo no futuro.

Como resumo desse movimento pendular heterogêneo, que é o euroceticismo interno à UE, lembre-se o que escreveu o historiador alemão Hagen Schulze, abertamente pró-Europa: "A Europa só foi capaz de se unir contra algo, nunca por algo. A Europa experimenta sua unidade sobretudo quando se trata de evitar um perigo comum, imaginário ou real, e perde essa unidade quando o perigo desapareceu" (SCHULZE 1995, p. 327).

A este respeito, a eliminação da ameaça imediatamente aparente da União Soviética não foi um bom presságio para o progresso do processo de integração europeia. Os alargamentos acelerados para vincular países do leste europeu (notadamente em 2004) já não foram acompanhados pelo processo de maturação que o projeto europeu requer.

No entanto, é preciso levar em conta que os perigos percebidos hoje não precisam mais ser de natureza militar. Vimos que os conflitos, que no passado muitas vezes levaram a complicações armadas, são mais provavelmente, em nosso tempo, travados no campo econômico - pense-se na tão invocada guerra comercial entre os EUA e a China, por exemplo. No domínio econômico, porém, existem razões suficientes para a Europa perceber perigos comuns, imaginários ou reais. Como bloco econômico, a União Europeia perdeu fôlego considerável em relação aos EUA e à China. Os mercados mundiais podem entrar em colapso por uma miríade de razões, materiais ou cibernéticas, fiscais ou sanitárias, como agora em 2020. No ambiente econômico, existem representações suficientes do inimigo para a União Europeia. Nesse aspecto, a 'Fortaleza Europa' também pode ter um aspecto positivo: a aliança defensiva que se observa é economicamente difícil, mas fortalece a identidade europeia.

Com efeito, a enquete realizada pela UE entre fevereiro e março de 2020 quanto à consciência europeia dos cidadãos aponta para o fato de que, mesmo que atitudes eurocéticas continuem a existir e a fazer ruído no espaço 
público, o sentimento filoeuropeu predomina de modo notável (Eurobarometer 2020). ${ }^{4}$

Nove entre dez entrevistados (91\%) de 2020 afirmam ter familiaridade com a expressão "cidadão da União Europeia" - 65\% afirmam conhecer a expressão e também saber o que significa. Tem-se aqui um crescimento de $4 \%$ com relação à enquete de 2015 e é o maior índice na série iniciada em 2007. Quanto a saber do que se trata, o crescimento é de 13\% (e também o nível mais alto desde 2007). Independentemente das posturas eurocéticas militantes, as taxas de consciência do pertencimento europeu são altas, como por exemplo na Itália (81\%), na Espanha (79\%), na Eslováquia (78\%), na Polônia (76\%), na Irlanda e na Áustria (ambos com 74\%). O conhecimento do teor da cidadania europeia (composta com a cidadania nacional) é particularmente elevado na Áustria (90\%), na Itália (89\%), na Espanha (88\%) e mais baixo na Lituânia (68\%), na Letônia (63\%) e na Romênia (59\%).

Pode-se assim concluir, mesmo que provisoriamente, que malgrado o ceticismo usual nas relações internacionais, sempre parece emergir um ou outro formato de entendimento e arranjo político, econômico, cultural ou social que torna viável uma espécie de otimismo de sobrevivência na complicada teia social e estatal existente na cena mundial (MARTINS, 2007).

\section{Referências}

CLARK, J. C. (2010). UK: A disunited kingdom. Em History Today. Vol. 60, Nr. 7.

DE VRIES, C. E. (2018). Euroscepticism and the Future of European Integration. Oxford University Press.

MARTINS, E. C. de R. (2007). Cultura e Poder. São Paulo: Saraiva, 2a . ed.

MARTINS, E. C. de R. (2012). Parcerias almejadas. Política externa, segurança, defesa e história na Europa. Belo Horizonte: Fino Traço.

MARTINS, E. C. de R. (2017). Democracy and the Threat of Populism. Estudos do Século XX (Coimbra), v. 17, p. 91-111.

MARTINS, E. C. de R. (2013). Parcerias intraeuropeias: 50 anos do Tratado do Eliseu (1963-2013). Revista Brasileira de Política Internacional (Impresso), v. 56 , p. $60-84$.

\footnotetext{
4 "European Union Citizenship and Democracy", Flash Eurobarometer 485, European Union, 2020
} 
MILIOPOULOS, L. (2017). "Europäisierter Euroskeptizismus? Eine theoretische Annäherung". Em: Frank Decker/Jürgen Rüttgers (orgs.): Europas Ende, Europas Anfang, Frankfurt a.M.: Campus.

SCHULZE, H. (1995). Staat und Nation in der europäischen Geschichte. Munique: C. H. Berck, 1995, 2a . ed. 